\title{
A Probabilistic Bulk Model of Coupled Mixed Layer and Convection. Part I: Clear-Sky Case
}

\author{
Pierre Gentine,* Alan K. Betts, ${ }^{+}$Benjamin R. Lintner, ${ }^{\#}$ Kirsten L. Findell, ${ }^{\circledR}$

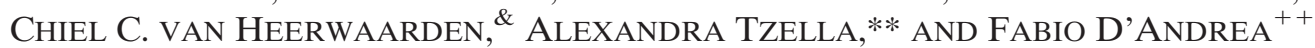 \\ * Columbia University, New York, New York \\ ${ }^{+}$Atmospheric Research, Pittsford, Vermont \\ ${ }^{\#}$ Rutgers, The State University of New Jersey, New Brunswick, New Jersey \\ @ Geophysical Fluid Dynamics Laboratory, Princeton, New Jersey \\ \& Max Planck Institute for Meteorology, Hamburg, Germany \\ ** School of Mathematics, University of Edinburgh, Edinburgh, United Kingdom \\ ${ }^{++}$Laboratoire de Meteorologie Dynamique, Paris, France
}

(Manuscript received 15 May 2012, in final form 11 January 2013)

\begin{abstract}
A new bulk model of the convective boundary layer, the probabilistic bulk convection model (PBCM), is presented. Unlike prior bulk approaches that have modeled the mixed-layer-top buoyancy flux as a constant fraction of the surface buoyancy flux, PBCM implements a new mixed-layer-top entrainment closure based on the mass flux of updrafts overshooting the inversion. This mass flux is related to the variability of the surface state (potential temperature $\theta$ and specific humidity $q$ ) of an ensemble of updraft plumes. The authors evaluate the model against observed clear-sky weak and strong inversion cases and show that PBCM performs well. The height, state, and timing of the boundary layer growth are accurately reproduced. Sensitivity studies are performed highlighting the role of the main parameters (surface variances, lateral entrainment). The model is weakly sensitive to the exact specification of the variability at the surface and is most sensitive to the lateral entrainment of environmental air into the rising plumes. Apart from allowing time-dependent top-ofthe-boundary-layer entrainment rates expressed in terms of surface properties, which can be observed in situ, PBCM naturally takes into account the transition to the shallow convection regime, as described in a companion paper. Thus, PBCM represents an important step toward a unified framework bridging parameterizations of mixed-layer entrainment velocity in both clear-sky and moist convective boundary layers.
\end{abstract}

\section{Introduction}

The top-of-the-boundary-layer entrainment velocitythat is, the development of convective boundary layer into the overlying stable free troposphere-plays a fundamental role in the height, temperature, and moisture states of the convective boundary layer (vanZanten et al. 1999). In the convective boundary layer, boundary-layertop entrainment is induced by upward thermals penetrating into the free troposphere (Hourdin et al. 2002; Rio and Hourdin 2008). The effect of these small-scale processes is parameterized in general circulation, regional, or mesoscale models. To date it has not been possible to

Corresponding author address: Pierre Gentine, Earth and Environmental Engineering, Columbia University, $500 \mathrm{~W} 120$ th St., New York, NY 10027.

E-mail:pg2328@columbia.edu develop a general parameterization of the entrainment process that bridges the transition from dry to cumulustopped boundary layers. The present study builds a unified framework for the dry and moist boundary layers in which hypotheses regarding the physical processes governing boundary layer-convection coupling can be easily tested.

In a recent position paper, Bony et al. (2011) emphasized the need for using models of differing levels of complexity to accelerate progress in climate modeling. In particular, simplified modeling should be used to close conceptual gaps at their source and try to develop process-level physical understanding. Bulk models have historically provided the basis for parameterizing the boundary layer in climate models for diagnostic studies or for deepening understanding of boundary layer processes (Stevens 2006) in the stratocumulus-topped (Lilly 1968; Deardorff 1976; vanZanten et al. 1999; Stevens 
2002, 2006), cumulus-topped (Betts 1973; Albrecht 1979; Albrecht et al. 1979; Bellon and Stevens 2005; Stevens 2006; Bretherton and Park 2008), or dry convective boundary layers (Betts 1973; Deardorff 1979; vanZanten et al. 1999).

In what follows, we construct a bulk formulation of the boundary layer in which boundary-layer-top entrainment velocity is related to the mass flux of an ensemble of updrafts overshooting the boundary layer inversion. We denote our formulation as the probabilistic bulk convection model (PBCM). The main idea behind PBCM is the realization that dry and shallow moist convection are probabilistic processes induced by turbulence originating from the surface. The variability at the surface induces variations in the properties of the rising plumes and in the boundary layer heights as observed in situ (Clayson and Kantha 2008) or in large-eddy simulations (Sullivan et al. 1998).

This first paper introduces the concepts behind the statistical growth of the mixed layer and how it is related to the surface variability for the case of a dry boundary layer without clouds. Over land, a dry boundary layer normally precedes the formation of shallow convection. Thus, a necessary starting point for a unified framework is the representation of a dry, cloud-free boundary layer. A companion paper (Gentine et al. 2013) extends the PBCM framework to a shallow cumulus boundary layer.

The rest of this paper is organized as follows. Section 2 summarizes the key elements of PBCM. Section 3 describes the variability of the surface and the new formulation of the entrainment at the boundary layer top. Section 4 details the prognostic equations of PBCM. Section 5 compares PBCM results with large-eddy simulations over weak and strong inversion cases. The model is then compared to observations over the Southern Great Plains (SGP) Atmospheric Radiation Measurement Program (ARM) Climate Research Facility for 5 June 1997. Section 6 presents results of sensitivity analyses in which some key PBCM parameters, including the surface variances and the lateral entrainment of the plume model, are varied.

\section{Model structure}

Figure 1 schematically illustrates the dry boundary layer structure assumed by PBCM. PBCM is a first-order dry mixed-layer model (e.g., Betts 1973, 1974; Deardorff 1979; vanZanten et al. 1999; Pino et al. 2006; Conzemius and Fedorovich 2007) and is divided into four continuous regions (from bottom to top):

1) The surface layer extending from the land surface to height $z_{\mathrm{SL}}$, which is here assumed to be $0.1 z_{m}$, where $z_{m}$ corresponds to the top of the mixed layer. In the

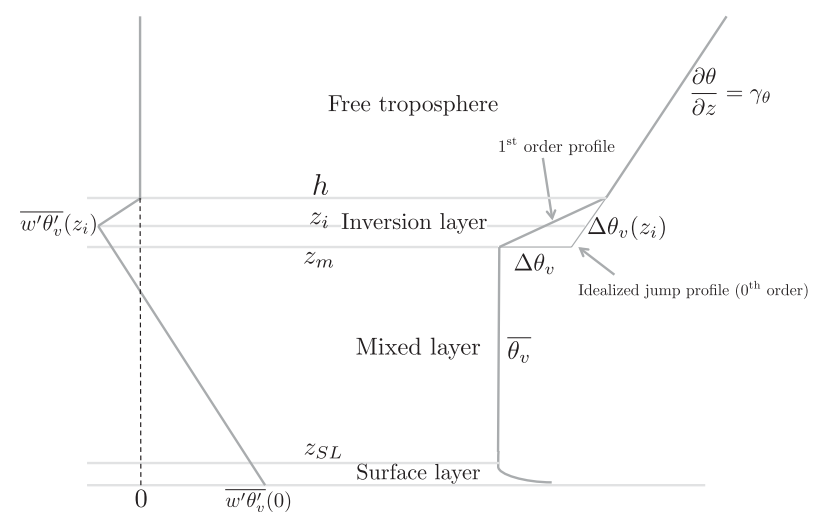

FIG. 1. Boundary layer structure.

surface layer the potential temperature and humidity profiles are logarithmic, with a Monin-Obukhov stability correction formulated as in Beljaars and Holtslag (1991).

2) The dry mixed layer extending from $z_{\mathrm{SL}}$ to $z_{m}$ in which $\theta$ and $q$ are assumed to be uniform.

3) The dry inversion layer connecting the mixed layer to the free troposphere between $z_{m}$ and $h$ with linear lapse rates $\Gamma_{\theta}\left(z_{m}\right)$ and $\Gamma_{q}\left(z_{m}\right)$.

4) The region above $h$ corresponds to the free troposphere where the constant lapse rates $\gamma_{\theta}$ and $\gamma_{q}$ of potential temperature and specific humidity are specified.

A list of symbols used can be found in Table 1.

PBCM has four variables requiring prognostic equations: $\bar{\theta}, \bar{q}, z_{m}$, and $h$.

\section{Variability at the surface and the evolution of the dry convective boundary layer}

We formulate the evolution of the dry convective boundary layer in PBCM by relating the top-of-theboundary-layer entrainment velocity to the mass flux of convective updrafts that originate from the surface and reach the level $h$. The advantage of this formulation is that the top-of-the-boundary-layer entrainment velocity does not require an ad hoc parameterization that is based on a linear relation between the buoyancy flux at the surface and the one at the top of the mixed layer: $\overline{w^{\prime} \theta_{v}^{\prime}}\left(z_{m}\right)=-\beta \overline{w^{\prime} \theta_{v}^{\prime}}(0) \quad($ Betts 1973; Tennekes 1973; Deardorff 1979; vanZanten et al. 1999; Pino et al. 2006; Conzemius and Fedorovich 2007), where the overbar denotes the Reynolds average, primes denote turbulent fluctuations, $w$ is the vertical velocity, $\beta$ is a constant whose value ranges from 0.1 to 0.2 , and $\theta_{v}$ is the virtual potential temperature. The new formulation relates the rate of growth of the mixed layer to the distribution of state variables at the surface (section $3 \mathrm{~d}$ ). These distributions can be observed in situ using eddy-covariance 
TABLE 1. List of variables and description.

\begin{tabular}{|c|c|c|}
\hline Variable & Description & Units \\
\hline$h$ & Boundary layer depth & $\mathrm{m}$ \\
\hline$q$ & Water vapor specific humidity & $\mathrm{kg} \mathrm{kg}^{-1}$ \\
\hline $\bar{q}$ & $\begin{array}{l}\text { Mean value of } q \text { in the dry } \\
\text { mixed layer }\end{array}$ & $\mathrm{kg} \mathrm{kg}^{-1}$ \\
\hline$T$ & Absolute temperature & $\mathrm{K}$ \\
\hline$w$ & Upward velocity & $\mathrm{m} \mathrm{s}^{-1}$ \\
\hline$\overline{w^{\prime} \phi^{\prime}}$ & $\begin{array}{l}\text { Vertical transport of conserved } \\
\text { variable } \phi\end{array}$ & $\mathrm{m} \mathrm{s}^{-1} \phi$ \\
\hline $\bar{X}$ & Ensemble-mean value of variable $X$ & - \\
\hline $\bar{X}^{u}$ & $\begin{array}{l}\text { Ensemble-mean value of variable } X \\
\text { over the updrafts }\end{array}$ & - \\
\hline$\overline{X^{\prime}}$ & $\begin{array}{l}\text { Turbulent deviation of } X \text { around } \\
\text { it mean statistical value } \bar{X}\end{array}$ & - \\
\hline$z_{\mathrm{SL}}$ & Surface-layer depth & $\mathrm{m}$ \\
\hline$z_{m}$ & Mixed-layer depth & $\mathrm{m}$ \\
\hline$\delta$ & $\begin{array}{l}\text { Depth of the inversion layer in the } \\
\text { first-order model }\end{array}$ & $\mathrm{m}$ \\
\hline$\gamma^{\theta}$ & $\begin{array}{l}\text { Potential temperature lapse rate } \\
\text { above the boundary layer }\end{array}$ & $\mathrm{K} \mathrm{m}^{-1}$ \\
\hline$\gamma^{q}$ & $\begin{array}{l}\text { Specific humidity lapse rate above } \\
\text { the boundary layer }\end{array}$ & $\mathrm{kg} \mathrm{kg}^{-1} \mathrm{~m}^{-1}$ \\
\hline$\Gamma_{z_{m}}^{X}$ & Lapse rate of $X$ right above level $z_{m}$ & - \\
\hline$\phi$ & Conserved variable $\phi=\{\theta, q\}$ & - \\
\hline$\rho$ & Air density & $\mathrm{kg} \mathrm{m}^{-3}$ \\
\hline$\theta$ & Potential temperature & $\mathrm{K}$ \\
\hline $\bar{\theta}$ & $\begin{array}{l}\text { Mean statistical value of } \theta \text { in } \\
\text { the dry mixed layer }\end{array}$ & $\mathrm{K}$ \\
\hline
\end{tabular}

measurements, while the mixed-layer entrainment velocity cannot.

\section{a. Surface variability}

The turbulence at the surface induces variability in the dry conserved variables $\mathbf{X}=[\theta q]^{\mathrm{T}}$ of the boundary layer. This variability is represented statistically through the definition of a joint probability density function (pdf) of $[w \theta q]$ as in Golaz et al. (2002), Cheinet $(2003,2004)$, and Neggers et al. (2009). For simplicity, this joint pdf is assumed to be Gaussian at height $z_{\mathrm{SL}}$, the lowest level of the mixed layer, and centered around the mean properties of the mixed layer: the large-scale vertical velocity $\bar{w}(z)$, the mean potential temperature $\bar{\theta}$, and the mean specific humidity $\bar{q}$. The values of $\bar{\theta}$ and $\bar{q}$ are determined by the budget equations, while the large-scale ascent $\bar{w}$ is prescribed.

The choice of a Gaussian pdf is obviously a rather strong assumption, although it has already been used and justified in previous work (e.g., Cheinet 2003, 2004; Kuang and Bretherton 2006; Neggers et al. 2009). More sophisticated pdf representations could be applied following, for example, Golaz et al. (2002) and Mellado et al. (2010). Our use of Gaussian pdfs is motivated by simplicity and analytical tractability. Furthermore, in PBCM we are only resolving the positively buoyant part of the distribution (updrafts), and we do not consider the downdrafts, which are often thought to impose a bimodal structure to the pdf (Golaz et al. 2002). Quantifying the actual distributions of turbulent variables remains an active area of research (e.g., Ansmann et al. 2010; Couvreux et al. 2010).

For a Gaussian distribution, the knowledge of its mean value and of the covariance matrix is sufficient to characterize the entire pdf. The surface covariance matrix is

$$
\Sigma=\left[\begin{array}{lll}
\overline{w^{\prime 2}} & \overline{w^{\prime} \theta^{\prime}} & \overline{w^{\prime} q^{\prime}} \\
\overline{w^{\prime} \theta^{\prime}} & \overline{\theta^{\prime 2}} & \overline{\theta^{\prime} q^{\prime}} \\
\overline{w^{\prime} q^{\prime}} & \overline{\theta^{\prime} q^{\prime}} & \overline{q^{\prime 2}}
\end{array}\right] .
$$

While the covariance matrix is specified at $z_{\mathrm{SL}}$, the boundary layer forcing is specified at the surface. The surface layer is characterized by relatively constant heat fluxes (Stull 1988; Garratt 1994). We therefore approximate the sensible and latent heat fluxes in the covariance matrix at $z_{\mathrm{SL}}$ by their surface values: $\overline{w^{\prime} \phi^{\prime}}\left(z_{\mathrm{SL}}\right) \approx \overline{w^{\prime} \phi^{\prime}}(0)$, with $\phi=\{\theta, q\}$.

For simplicity, we assume that the vertical turbulent kinetic energy term $\overline{w^{\prime 2}}$ and the variances of potential temperature $\overline{\theta^{12}}$ and humidity $\overline{q^{12}}$ are obtained through a similarity relationship. We assume $\overline{w^{\prime 2}}=0.33 w_{*}^{2}$ based on Stull (1988). The convective velocity scale is defined as $w_{*}=\left[g z_{m} \overline{w^{\prime} \theta_{v}^{\prime}}(0) / \overline{\theta_{v}}\right]^{1 / 3}$ as in Deardorff (1979). Following Stull (1988) it is also assumed that $\overline{\theta^{\prime 2}}=5 \theta_{*}^{2}$ and $\overline{q^{\prime 2}}=5 q_{*}^{2}$, with $\theta_{*}=\overline{w^{\prime} \theta_{v}^{\prime}}(0) / w_{*}$ and $q_{*}=\overline{w^{\prime} q^{\prime}}(0) / w_{*}$. A sensitivity study on the surface variance is performed in section 6 .

As in De Bruin et al. (1999), the correlation between $\theta^{\prime}$ and $q^{\prime}$ is assumed to be 1 . This correlation evolves above the surface into the boundary layer because of the environmental mixing but generally remains positive in the updrafts (Lenschow 1973; Lothon et al. 2007), while it is the tropospheric downdrafts penetrating into the surface layer that reduce it. Since the updrafts explicitly determine boundary layer growth (see section 3d), we do not consider here the structure of the downdrafts.

Note that the sensible $\left(\overline{w^{\prime} \theta^{\prime}}\right)$ and latent $\left(\overline{w^{\prime} q^{\prime}}\right)$ heat fluxes not only determine variability at the surface (through the similarity relationships) and the cross variations of those variables but they also determine the evolution of the mean (bulk) mixed-layer state variables through the common heat and moisture conservation laws (see next section).

\section{b. Height evolution of the updraft properties: $w, \theta$, and $q$}

To compute the mass flux at level $h$, we need to determine the distribution of the updraft velocity above the inversion. The updrafts originate from the surface. 
The conserved variables of the updrafts during their vertical evolution are computed using an entraining plume model (Simpson et al. 1965; Simpson and Wiggert 1969; Betts 1975; Hourdin et al. 2002; Siebesma et al. 2003; Soares et al. 2004). Each updraft is described by its moist conserved variables $\theta_{l}, q_{\mathrm{tot}}$-respectively the liquid water potential temperature and the total water-and by its vertical velocity $w_{u}$. Within an updraft, the vertical structure of a conserved variable is determined by

$$
\frac{d \phi_{u}}{d z}=-\epsilon\left(\phi_{u}-\bar{\phi}\right)
$$

where $\epsilon$ is the lateral entrainment rate, $\phi_{u}$ refers to the moist conserved variables of the updraft (i.e., $\left\{\theta_{l}, q_{\text {tot }}\right\}$ ), and $\bar{\phi}$ refers to the conserved variable of the mixed layer. The lateral entrainment rate is assumed to scale with the depth of the mixed layer as $c_{\epsilon} / z_{i} \mathrm{~m}^{-1}$, with $c_{\epsilon}=1$ (De Rooy and Siebesma 2008).

For the updraft velocity we have

$$
\frac{1}{2} \frac{d w_{u}^{2}}{d z}=c_{1} B(z)-c_{2} \epsilon w_{u}^{2},
$$

with $c_{1}=1 / 3$ and $c_{2}=2$ as in Jakob and Siebesma (2003) and with $B(z)=g / \overline{\theta_{v}}\left(\theta_{v}^{u}-\overline{\theta_{v}}\right)$ the updraft buoyancy.

These equations can be integrated analytically as detailed in the appendix. By a Monte Carlo analysis (not shown), the dependence on the value of $w$ at the surface can be shown to be small and is neglected, so that the vertical profile of the velocity is only dependent on the surface virtual temperature anomaly $\theta_{v}^{\prime}(0)$. Since the specific humidity and potential temperature of the updrafts are perfectly correlated at the surface the standard deviation of $\theta_{v}^{\prime}(0)$ is simply $\sigma_{\theta_{v}}=\sigma_{\theta}+\bar{\theta} \gamma \sigma_{q}$, in which $\gamma$ is the ratio of water vapor to dry air density. Consequently, PBCM can be expressed in terms of the surface distribution of virtual temperature anomalies $\theta_{v}^{\prime}(0)$.

\section{c. Updraft fraction and mass flux overshooting the inversion}

In addition to the vertical velocity of the updrafts, the fractional cover of the updrafts is needed to compute the mass flux of the updrafts overshooting the inversion. We assume that the fractional cover of each updraft is unchanged in the mixed layer. In the inversion, some of the updrafts overturn because of the negative buoyancy acting on them [see Eq. (3)]. The total updraft cover within the inversion is thus reduced. The total fractional cover of the updrafts overshooting the inversion $h, f_{u}$, is obtained by integrating the surface distribution above the dry convective inhibition (CIN) threshold $\theta_{v, h}^{\prime}$, defined as the minimum buoyancy anomaly necessary to reach $h$ :

$$
f_{u}=\frac{1}{2} \operatorname{erfc}\left(\frac{\theta_{v, h}^{\prime}}{\sqrt{2} \sigma_{\theta_{v}}}\right)
$$

Figure 2 depicts the dry CIN threshold and how it is reflected in the vertical kinetic energy of the updraft above the inversion. Because of the linear transformation of the surface distribution, the vertical kinetic energy of the updraft remains Gaussian above the inversion. The negative side of the vertical kinetic energy pdf (white area in Fig. 2) is not used since it corresponds to updrafts that are unable to reach the top of the inversion.

The dry CIN threshold is computed as the surface virtual potential temperature threshold such that $w_{u}(h)=0$ :

$$
\theta_{v, h}^{\prime}=\frac{1}{2} \frac{\left[2 c_{2} e^{-\epsilon\left(h-z_{m}+2 c_{2} z_{m}\right)}-2 c_{2} e^{-2 c_{2} \epsilon z_{m}}-e^{-2 c_{2} \epsilon h}+e^{-2 c_{2} \epsilon z_{m}}\right] \Gamma_{z_{m}}^{\theta_{v}} e^{2 c_{2} \epsilon z_{m}}}{\left(e^{-2 c_{2} \epsilon h}-e^{-\epsilon h}\right) \epsilon c_{2}},
$$

which simply tends to

$$
\theta_{v, h}^{\prime}=\frac{1}{2} \frac{\Gamma_{z_{m}^{v}}^{\theta_{v}}\left(h-z_{m}\right)^{2}}{h}
$$

in the absence of lateral entrainment (when $\epsilon$ goes to 0 ). This threshold corresponds to the dry CIN to reach the inversion layer top for a nonentraining parcel.

The updraft mass flux at level $h$ is then obtained as the updraft ensemble mean:

$$
M_{u}(h)=\rho \overline{f_{u} w_{u}}=\rho \overline{f_{u}} \bar{w}_{u}^{u},
$$

where $\overline{f_{u}}$ is the fractional cover of overshooting updrafts, ${\overline{w_{u}}}^{u}$ represents the average value of the updraft convective velocity, and $w_{u}$ conditioned on being an overshooting updraft [obtained from Eq. (3)].

\section{d. A new parameterization for the} boundary-layer-height entrainment velocity

The top-of-the-dry-boundary-layer entrainment velocity is defined as

$$
w_{e}=\frac{d h}{d t}-\bar{w}(h)
$$

where $\bar{w}$ represents the large-scale upward velocity. 


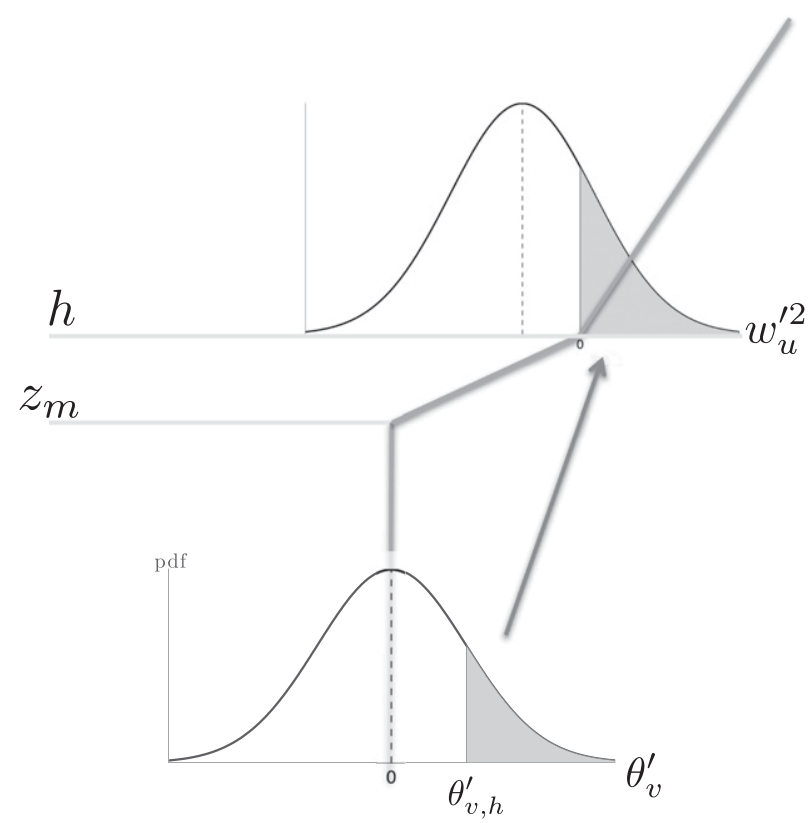

FIG. 2. Schematics describing how the probability density function in virtual potential temperature anomaly is transformed into vertical velocity at the inversion. To reach the inversion the updrafts must have an initial buoyancy anomaly $\theta_{v}^{\prime} \geq \theta_{v, h}^{\prime}$.

We here present a new parameterization of the entrainment process at the boundary layer top. In this parameterization we assume that entrainment is done by sinking free-tropospheric air motion only. In turn, the mass flux of this sinking motion equals the mass flux of the updrafts overshooting $h$, which was computed in Eq. (7). We here want to stress that at level $h$ the buoyancy flux is assumed to be negligible through compensating ascending and descending turbulent motion yet the TKE and therefore mass flux is generally nonnull at this height [see Fig. 4 in Sullivan et al. (1998)], especially in the weak stratification case.

Like any other parameterizations, the boundary layer entrainment closure in Eq. (11) grossly simplifies the detailed turbulence structure inherent to the entrainment process at the boundary layer top; nevertheless, this closure is consistent with several observed aspects of entrainment. Because entrainment is statistical in nature (Clayson and Kantha 2008), adopting a probabilistic approach is legitimate. Based on scaling analysis and the use of the Ozmidov length scale (Dillon 1982), which is a measure of the length scale of turbulent overturning events, it is expected that small eddies will dissipate rapidly within the inversion. Larger eddies and the most intense updrafts will therefore penetrate deeper into the stable inversion. In the convective boundary layer, most of the turbulent transport is induced by coherent structures such as thermal plumes (Couvreux et al. 2010). The

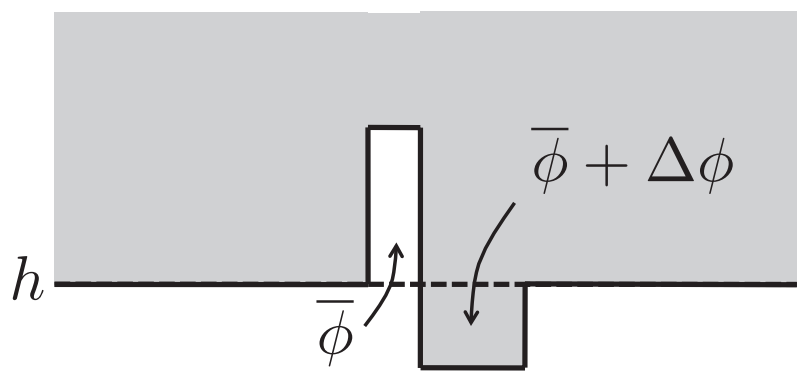

FIG. 3. Schematics of the mechanism of entrainment of free-tropospheric air into the mixed layer.

transport of smaller eddies is much smaller. Finally, based on the quadrant analysis of Sullivan et al. (1998), “ . . in the entrainment zone upward-moving thermal plumes, which are cool relative to their surroundings, make up a large fraction of the negative heat flux, but because of the stable stratification these same plumes eventually are redirected downward and then become large contributors to positive buoyancy flux. In other words, to a large extent plumes generate a self-canceling buoyancy flux in the entrainment zone... . Thus, net entrainment is associated mainly with quadrant IV motions, that is, warm air moving downward (free-tropospheric downward motion)" (p. 3054).

Inspired by the work of Stull $(1973,1976 b)$ and Sullivan et al. (1998), we hypothesize that every updraft overshooting the inversion creates a fold ["a dome" in the terminology of Stull (1973)] of the surface of the inversion. In this process, pockets of free-tropospheric air are trapped and mixed downward into the boundary layer. This is shown schematically in Fig. 3 [cf. with Sullivan et al. (1998)]. The mass transport of the updraft is given by its vertical velocity multiplied by its density and its fractional cover. Since mass is conserved, this updraft mass is equal to the mass trapped into the sinking pocket [as shown in Stull (1973), (1976b)]:

$$
\rho f_{u} w_{u}=\rho f_{p} w_{p}
$$

where $w_{p}$ and $f_{p}$ are the vertical velocity of the pocket and its fractional cover, respectively.

Taking the ensemble mean of Eq. (9) yields

$$
\rho \overline{f_{u} w_{u}}=\rho \overline{f_{p} w_{p}} .
$$

We define $w_{e} \equiv \overline{f_{p} w_{p}}$ as our top-of-the-boundary-layer entrainment velocity.

Since the lhs of Eq. (10) is the updraft mass flux, the entrainment velocity is equal to the mass flux of the overshooting updrafts:

$$
\rho w_{e}=M_{u}(h) .
$$


The detailed analytical derivation is provided in the appendix.

In reference to the schematics in Fig. 3, we can also write the transport of a conserved variable $\phi$ in the pocket as $-\rho f_{p} w_{p} \Delta \phi$, calling $\Delta \phi$ the jump in $\phi$ across the inversion. Taking again the ensemble mean gives the turbulent transport of $\phi$ by all the pockets of sinking free-tropospheric motion:

$$
\rho \overline{w^{\prime} \phi_{p}^{\prime}}=-\rho \overline{f_{p} w_{p}} \Delta \phi=-\rho w_{e} \Delta \phi
$$

The overshooting updrafts eventually overturn into the boundary layer as downdrafts, yielding no net mass, heat, or moisture transport (Sullivan et al. 1998, and discussion above). The net turbulent transport is thus due to the entrained pockets of free-tropospheric air only (Stull 1973, 1976b; Sullivan et al. 1998); that is,

$$
\overline{w^{\prime} \phi^{\prime}}\left(z_{m}\right)=-\overline{f_{p} w_{p}} \Delta \phi=-w_{e} \Delta \phi
$$

In this form, it clearly appears that our definition of the entrainment velocity is the same as typical formulations (Betts 1973, 1974; Deardorff 1979). We note that we have neglected the effect of upward-propagating waves induced by the overshooting convective elements (Stull 1976b). This effect is small in the convective boundary layer and accounts for less than $10 \%$ of the turbulent kinetic budget when $\Delta \theta_{v} / w_{*}<0.5 \mathrm{~K} \mathrm{~s} \mathrm{~m}^{-1}$ (Stull 1976b), which is usually the case except during the earliest growth stage of the boundary layer. It should be emphasized that this entrainment parameterization can be seen as a generalization to a continuum of thermals of the single diagnostic plume used in typical mass-flux parameterizations of the dry mixed layer (e.g., Neggers et al. 2009).

We have derived this new entrainment parameterization with the aim of unification with updraft mass-flux approaches (Lappen and Randall 2001; Hourdin et al. 2002). This parameterization then permits to couple the entrainment velocity with the cloud-base mass flux in the presence of moist convection, as we discuss in a companion paper (Gentine et al. 2013). This new entrainment formulation represents an important step toward a unified framework bridging parameterizations of mixed-layer entrainment velocity and mass flux in both clear-sky and moist convective boundary layers.

\section{Prognostic equations of dry boundary layer}

The dry, bulk, boundary layer requires prognostic equations for the evolution of the four state variables: $\bar{\theta}$, $\bar{q}, z_{m}$, and $h$. The rate of growth of $h$ was obtained in the previous section.

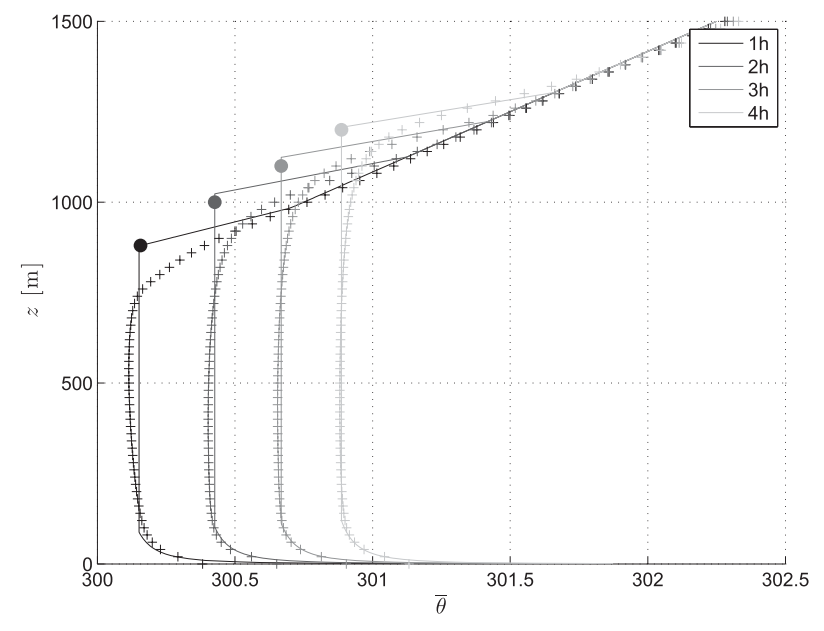

FIG. 4. Temporal evolution of the dry convective boundary layer with the probabilistic model for the weak-convective-boundarylayer case of Sullivan et al. (1998). The large dots correspond to the level of zero buoyancy flux, which is used as a diagnostic of the mixed layer in the LES, following Fedorovich et al. (2004). Continuous line represents the bulk model results and crosses represent the large-eddy simulation outputs. Solid black line represents the initial profile.

\section{a. Mixed-layer growth}

Once $h$ is found, we need to compute $z_{m}$. In a first-order model $z_{m}$ cannot correspond to the minimum buoyancy flux level $z_{i}$ since the minimum buoyancy flux level is located near the middle of the inversion (vanZanten et al. 1999). Here we define $z_{m}$ as the level of zero-buoyancy flux, similar to Fedorovich et al. (2004). To find $z_{m}$ we use an approach inspired by Betts (1973) for shallow convection. The zero-buoyancy flux is diagnosed as the level of neutral buoyancy (LNB) of a diagnostic updraft where $\theta_{v}^{u}(\mathrm{LNB})=\theta_{v}^{\text {env }}(\mathrm{LNB})$. This updraft has properties averaged across all updrafts (i.e., $\theta_{v}^{\prime}>0$ ) and therefore has a potential temperature anomaly at the surface $\sigma_{\theta} / \sqrt{2 \pi}$ and humidity $\sigma_{q} / \sqrt{2 \pi}$. The rate of growth of the mixed layer is found using the eddy overturning time scale $\tau=z_{m} / w_{*}$ :

$$
\frac{d z_{m}}{d t}=\frac{\mathrm{LNB}-z_{m}}{\tau}+\bar{w}\left(z_{m}\right) .
$$

We tested the dependence of PBCM on $\tau$ and our results are almost insensitive to the exact definition of $\tau$.

In the literature, there exist formulations to diagnose the depth of the inversion layer (e.g., Deardorff and Willis 1980; Fedorovich et al. 2004; Neggers et al. 2007, 2009) and therefore to obtain the mixed-layer depth once $h$ is known. The formulation of Neggers et al. (e.g., Neggers et al. 2007, 2009) does not account for the lateral entrainment, yet lateral entrainment modifies the velocity at the top of the mixed layer, which will impact 
(a)

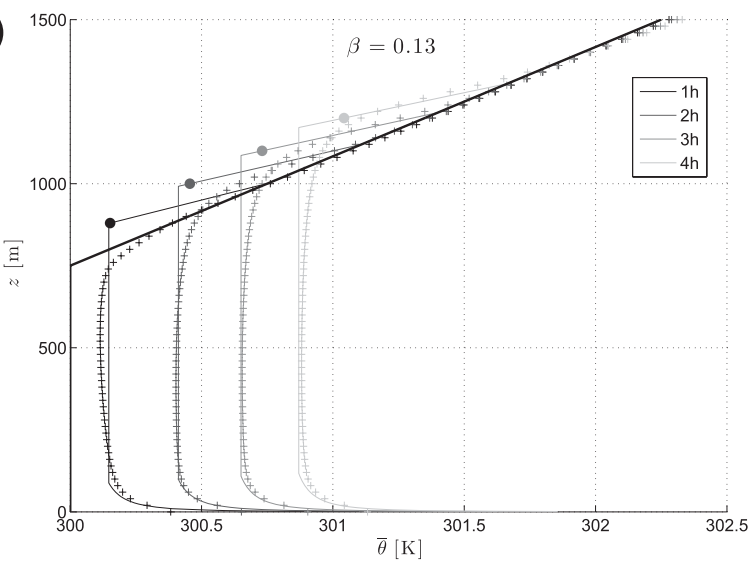

(b)

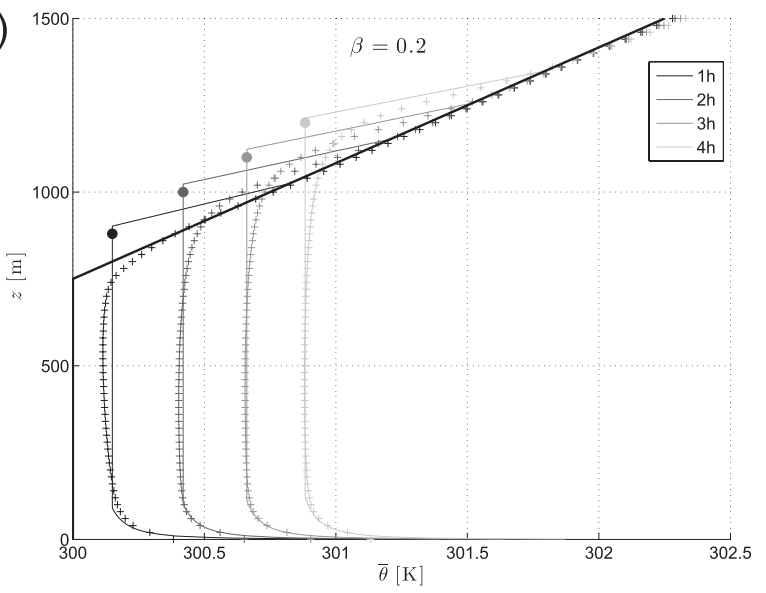

FIG. 5. As in Fig. 4, but with (a) $\overline{w^{\prime} \theta_{v}^{\prime}}\left(z_{m}\right)=-0.13 \overline{w^{\prime} \theta_{v}^{\prime}}(0)$ and (b) $\overline{w^{\prime} \theta_{v}^{\prime}}\left(z_{m}\right)=-0.2 \overline{w^{\prime} \theta_{v}^{\prime}}(0)$ entrainment formulation for the weakconvective-boundary-layer case of Sullivan et al. (1998).

the depth of the inversion layer when using a parcel energy conservation argument in the inversion layer (Batchvarova and Gryning 1994; Neggers et al. 2007, 2009). Other formulations relating directly the inversion layer depth to the Richardson number (e.g., Deardorff and Willis 1980; Fedorovich et al. 2004) have difficulties representing the transition to moist convection since the bulk values of the environmental profiles are not much modified by the presence of the cloud cover.

\section{b. Heat and moisture budget}

In the dry mixed layer, longwave radiation is assumed negligible during daylight hours. The mixed-layer bulk conservation equation thus reads (e.g., Deardorff 1979; vanZanten et al. 1999; Stevens 2006)

$$
z_{m} \frac{d \bar{\phi}}{d t}=\overline{w^{\prime} \phi^{\prime}}(0)+w_{e} \Delta \phi\left(z_{m}\right)
$$

with $\bar{\phi}=\{\bar{\theta}, \bar{q}\}$, and $\Delta \phi\left(z_{m}\right)$ is the jump of $\phi$ at the mixedlayer top computed as $\Delta \phi\left(z_{m}\right)=\phi(h)-\Gamma_{z_{m}}^{\phi}\left(h-z_{m}\right)$, as in vanZanten et al. (1999).

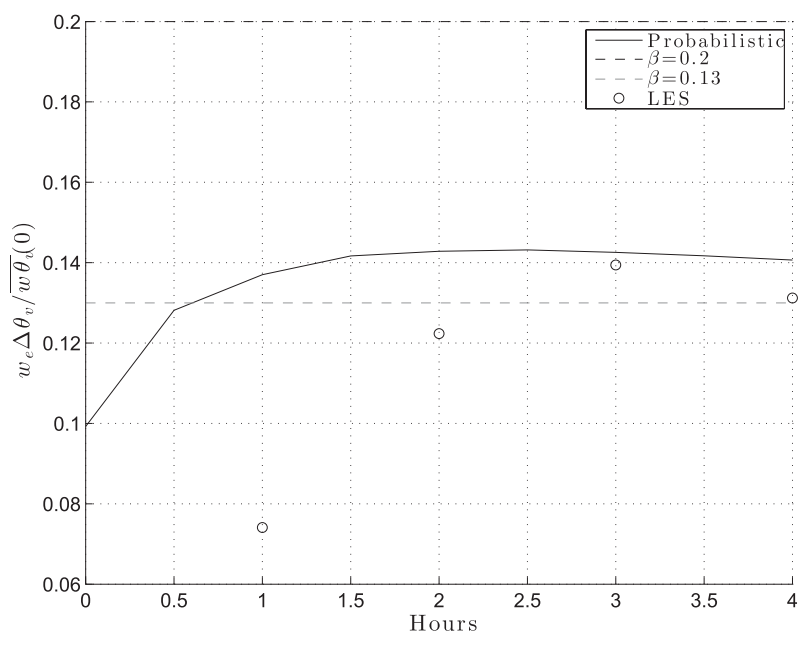

FIG. 6. Relative entrainment velocity of the pdf model compared to the LES results and to the constant $\beta$ formulations.

\section{Comparison with LES data}

\section{a. Synthetic dataset: Weak inversion case}

PBCM is first evaluated against the large-eddy simulation (LES) synthetic dataset of Sullivan et al. (1998) of a dry (no moisture) free convective boundary layer with a weak inversion (case W06) using the Dutch LES (Heus et al. 2010). The reader is referred to Sullivan et al. (1998) for a detailed description of the experiment.

Figure 4 represents the result of the new pdf-based entrainment velocity closure without any tuning. The large dots represent the diagnostic of the mixed-layer height in the large-eddy simulation run as the zerobuoyancy flux (Fedorovich et al. 2004). The pdf model accurately represents both the mixed-layer height and the value of potential temperature in the mixed layer. This formulation presents negligible additional computational burden relative to the constant $\beta$ formulations since it can be computed analytically. Note that the assumed linear profile in the inversion layer does not allow for a perfect fit of the curvature observed in large-eddy simulations. This is a fundamental limitation of any firstorder model, not just of PBCM itself.

The results are compared to typical constant $\beta$ formulations. We here consider two typical formulations for the $\beta$ factor: 1 ) a typical constant $\beta=0.2$ value [as in Stull (1976a)] and 2) the constant $\beta \approx 0.13$ formulation introduced by Deardorff (1979). A detailed comparison of these formulations is described in vanZanten et al. (1999). Figure 5 depicts the response of the bulk model with a $\beta$-entrainment parameterization, with $\beta=0.13$ (Fig. 5a) or $\beta=0.2$ (Fig. 5b). For both values of $\beta$ the rate of growth of the mixed layer is estimated correctly. In the constant $\beta$ runs the inversion depth is plotted 


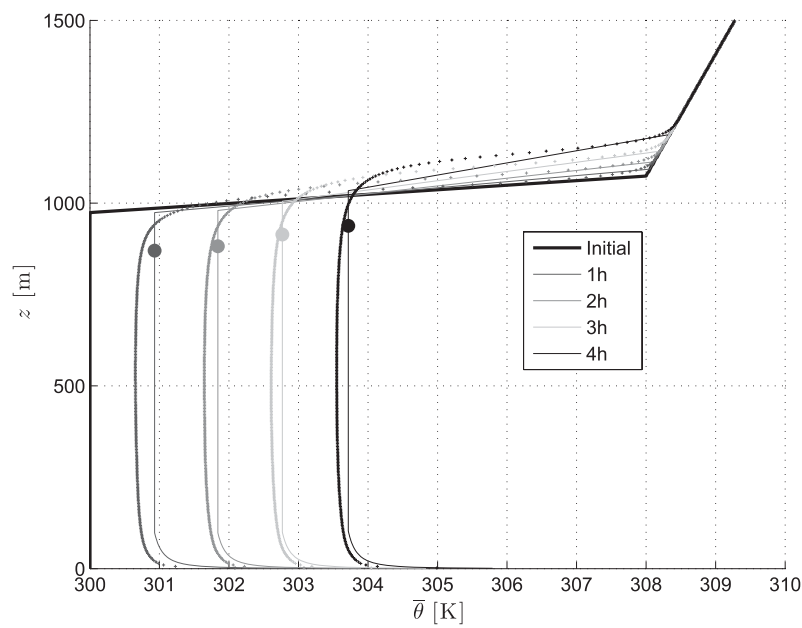

FIG. 7. Temporal evolution of the dry convective boundary layer with the probabilistic model for the strong-convective-boundarylayer case of Sullivan et al. (1998). The large dots correspond to the level of zero buoyancy flux, which is used as a diagnostic of the mixed layer in the LES, following Fedorovich et al. (2004). Continuous line represents the bulk model results and crosses represent the large-eddy simulation outputs. Solid black line represents the initial profile.

using the parameterization of Neggers et al. (2009) yet this depth is not explicitly used in this 0th-order model since the free-tropospheric profile is extended up to the mixed-layer top. The inversion is just plotted for illustrative purpose in comparison with PBCM.

To get further insights on the daytime variability of the entrainment ratio $\beta$, the $\beta$ factor of PBCM is plotted against typical $\beta$ formulations and LES estimates in Fig. 6 . At the beginning of the run, corresponding to the main growth of the boundary layer, the $\beta$ factor is lower than Deardorff (1979)'s (0.13) and the typical (0.2) value, as observed with the LES study. No model is favored under those conditions. It should be noted that in the earlier period of the run the LES turbulence still has to spin up and can thus underestimate the entrainment process. In addition, during the growth period of the convective boundary layer the dissipation of turbulent kinetic energy through internal wave dissipation can be important (Stull 1976b) and is not represented in either of the bulk models.

\section{b. Synthetic dataset: Strong inversion case}

PBCM is further tested in the case of a dry convective boundary layer with a strong inversion (Sullivan et al. 1998) compared to results from the Dutch LES. PBCM compares favorably with the LES outputs as observed in Fig. 7. The mixed-layer potential temperature is correctly represented as well as the depth of the mixed layer. This result confirms the applicability of the new boundarylayer-top closure under a strong inversion. The constant $\beta$ (a)

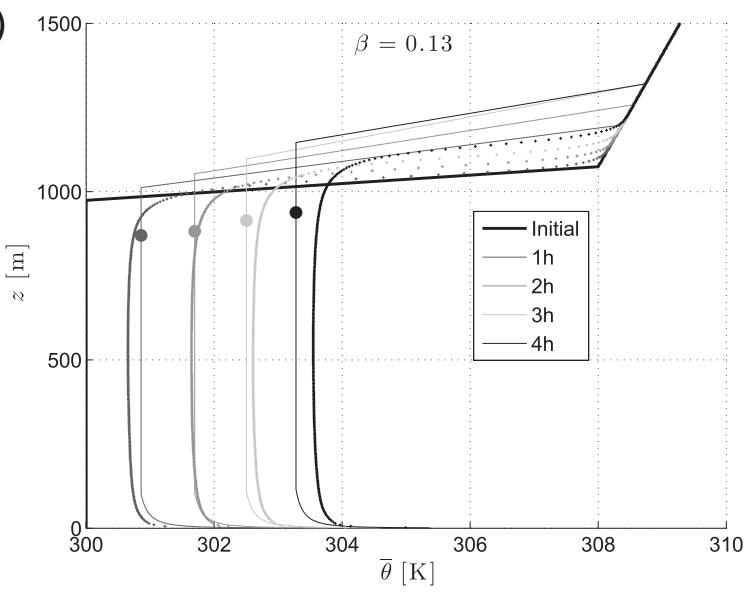

(b)

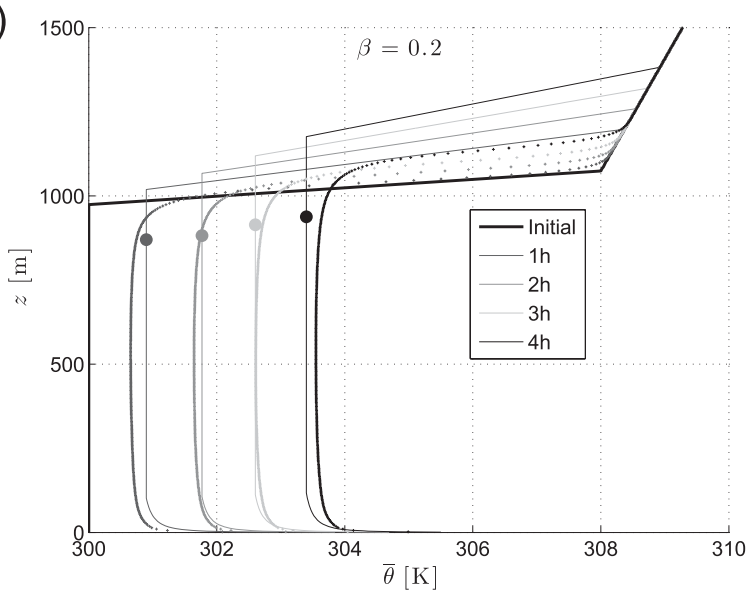

FIG. 8. As in Fig. 7, but with (a) $\overline{w^{\prime} \theta_{v}^{\prime}}\left(z_{m}\right)=-0.13 \overline{w^{\prime} \theta_{v}^{\prime}}(0)$ and (b) $\overline{w^{\prime} \theta_{v}^{\prime}}\left(z_{m}\right)=-0.2 \overline{w^{\prime} \theta_{v}^{\prime}}(0)$ entrainment formulation for the weak convective boundary layer case of Sullivan et al. (1998).

formulations are also plotted in Fig. 8 for comparison. The $\beta$ formulations tend to overestimate the depth of the mixed layer and to underestimate the mixed-layer potential temperature.

\section{c. Dataset: SGP 5 June 1997}

The SGP Cloud and Radiation Testbed (CART) is operated by the U.S. Department of Energy as part of ARM. The site consists of in situ and remote sensing instrumented clusters arrayed across approximately $140000 \mathrm{~km}^{2}$ in Oklahoma and Kansas. Measurements are taken at the Central Facility.

We have selected 5 June 1997 as a typical clear-sky day with the development of a convective boundary layer (Santanello et al. 2005). Negligible large-scale advection and convergence forcing were present. During that day intensive measurements of the boundary layer height were performed.

The surface turbulent sensible and latent heat fluxes were measured by eddy correlation (EC). The surface 

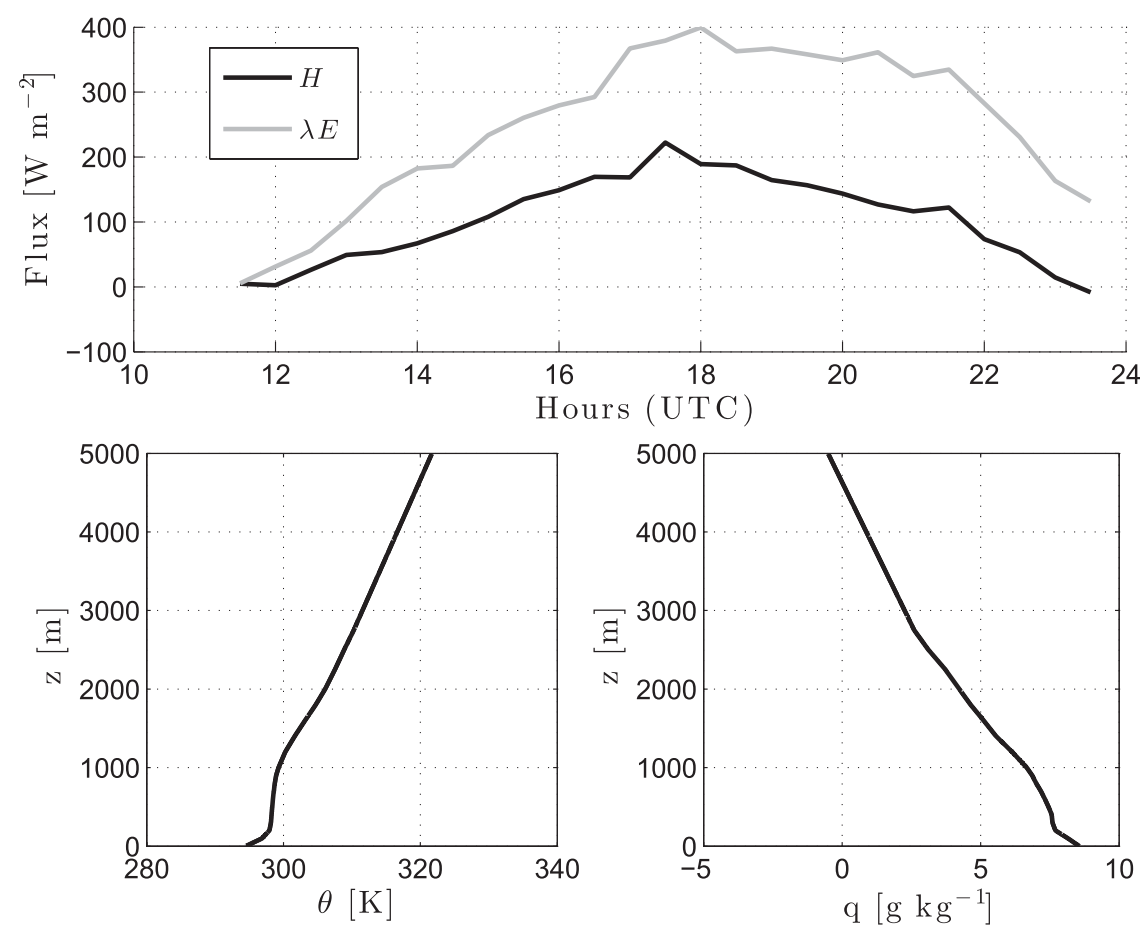

FIG. 9. (top) Surface sensible heat flux $H$ and latent heat flux $\lambda E$, and (bottom left) initial potential temperature and (bottom right) specific humidity profiles for 5 Jun 1997 for the ARM SGP site in Oklahoma.

heat fluxes are depicted in Fig. 9. The model is forced with the observed initial profile and the time series of turbulent heat fluxes at the surface.

Radiosondes were launched at 1130 UTC (0630 LT), 1430 UTC (0930 LT), 1730 UTC (1230 LT), 2030 UTC (1530 LT), and 2330 UTC (1830 LT) during the experiment. The sondes measured dry- and wet-bulb temperatures and pressure. PBCM was initialized on 5 July with the observed sounding obtained from the radiosondes at 1130 UTC, which are seen in Fig. 9.

The temperature and humidity profiles are compared to observations obtained from radiosondes. Figures 10 and 11 compare the probabilistic modeled profile (continuous line), $\beta=0.2$ (plus sign), Deardorff $\beta \approx 0.13$ (circles), to radiosonde (dashed line) data.

At 1730 UTC (1230 LT), there is good agreement between all models and observation as seen in Fig. 10. All models are in very good agreement with the potential temperature and humidity sounding in the boundary layer (until $1300 \mathrm{~m}$ ). There is substantial increase in the observed potential temperature in the free troposphere, which cannot be captured by the model since the profile was imposed at the beginning of the run. At 2030 UTC (1530 LT), the mixed layer of PBCM is in slightly better agreement with observations. In particular the $\beta=0.2$ model overestimates the mixed-layer height by about $100 \mathrm{~m} ; \beta=0.13$ formulation overestimates the mixed-layer height by about $50 \mathrm{~m}$. This further confirms that $\mathrm{PBCM}$ is able to realistically reproduce the observed profiles.

\section{Sensitivity tests \\ a. Model parameters: Similarity closure}

Parameter-sensitivity tests have been performed to determine the flexibility and validity of the results of PBCM. The model sensitivity is here tested over the ARM case to investigate both the moisture and temperature dependence of the formulation. The main parameters of PBCM, the similarity coefficients of the variances of $\theta$ and $q$ at the surface, are increased by $50 \%$. The first test increases the variance of the vertical velocity of the plume pdf, the second test increases the variance of potential temperature, the third test increases the variance of specific humidity, and a final test increases the lateral entrainment rate.

A summary of the sensitivity test is reported in Table 2. The sensitivity is shown for three variables: the daylighthour maximum specific humidity $[\max (q)]$, the maximum potential temperature $[\max (\theta)]$, and the maximum height of the mixed layer $\left[\max \left(z_{m}\right)\right]$.

The runs with increased vertical velocity variance are indiscernible from the reference run. The $50 \%$ increase in potential temperature variance leads to a $1 \%$ decrease 


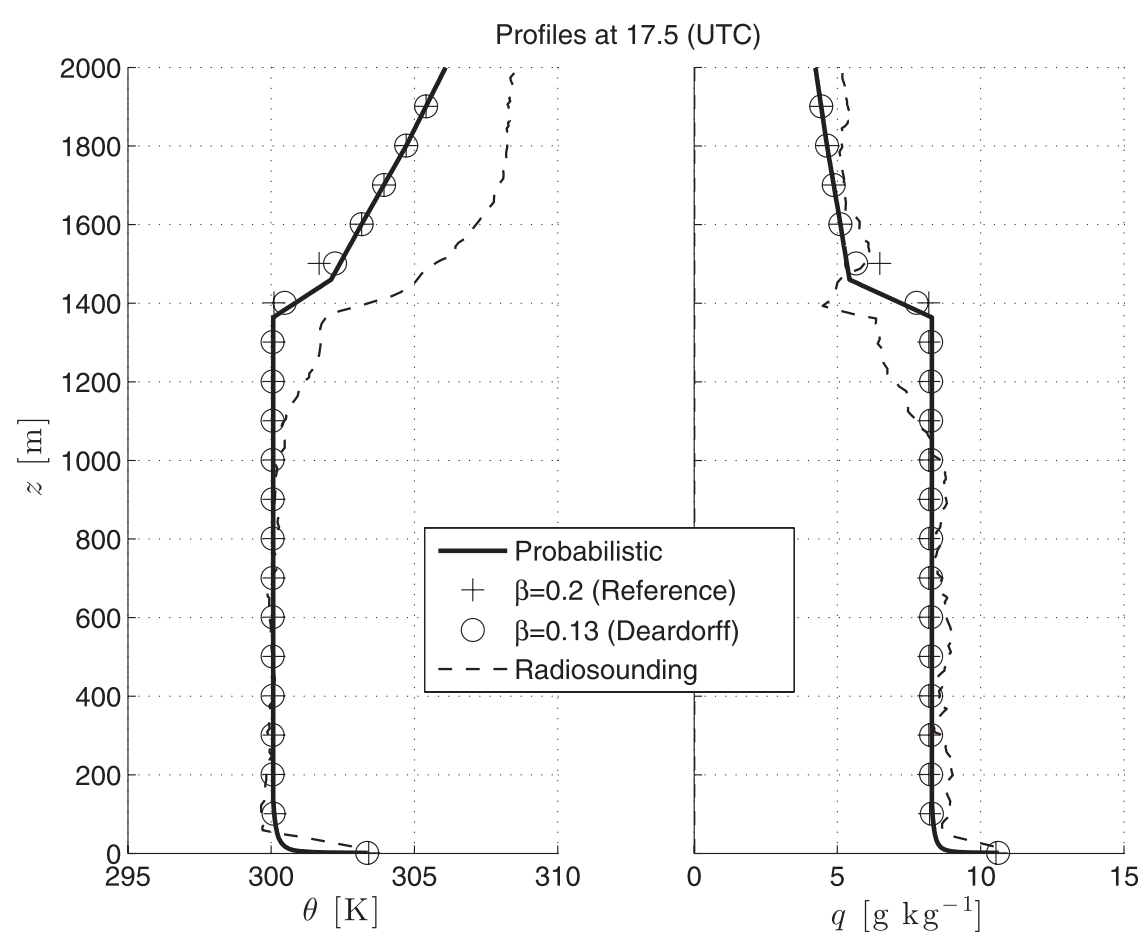

FIG. 10. Profiles of (left) potential temperature and (right) specific humidity at 1730 UTC 5 Jun 1997 for the ARM SGP site in Oklahoma.

in specific humidity. The mixed-layer maximum height increases by $2 \%$ because of the increased buoyancy of the plumes. The mixed-layer potential temperature is not sensitive to the increased variance. When the potential temperature variance is doubled or quadrupled, respectively, the boundary layer maximum depth increases by $4 \%$ and $8 \%$, the maximum mixed-layer potential temperature decreases by 0.1 and $0.2 \mathrm{~K}$, and the maximum mixed-layer specific humidity increases by $2 \%$ and $4 \%$. This latter increase in specific humidity should be compared with the reduction in the $50 \%$ increase case, which points to a nonlinear response of specific humidity.

As could be expected, lateral entrainment is the most important model parameter. An increase of the lateral entrainment by $50 \%$ leads to a $6 \%$ reduction of the maximum boundary layer height. A $50 \%$ reduction of the lateral entrainment leads to a mixed-layer $16 \%$ larger than in the reference case. This asymmetric response emphasizes the nonlinearity of the response to the lateral entrainment. The maximum potential temperature in the mixed layer decreases by $0.077 \mathrm{~K}$ with the increased lateral entrainment. The maximum specific humidity is increased by $2 \%$.

\section{b. Environmental profile lapse rate: Weak $C B L$}

The lapse rate of the initial potential temperature profile of the weak CBL case is increased by $1 \mathrm{~K} \mathrm{~km}^{-1}$ from the surface up in order to evaluate the sensitivity of the boundary layer model to the environmental stability. Figure 12 depicts the influence of this lapse-rate increase on the mixed-layer growth and potential temperature.

The increased stability in the initial atmospheric profile leads to a strong reduction of the mixed-layer growth. This reduction plateaus at $-7 \%$ of the reference run after $4 \mathrm{~h}$ of simulation with PBCM. Results from the constant $\beta$ formulations are very similar and are not depicted for clarity. The Dutch LES reduction also reached $-7 \%$ at the end of the simulation (not shown).

The mixed-layer potential temperature is almost not impacted by a change in the atmospheric stability with a very slight increase of about $0.048 \mathrm{~K}$ induced by the warmer air entrainment on top of the mixed layer. The Dutch LES gives an increase of $0.042 \mathrm{~K}$. The potential temperature is relatively insensitive to the magnitude of the entrainment process.

These sensitivity tests emphasize the fundamental role of the inversion layer acting as a regulator of heat exchange in the system through the control of the dry convective inhibition, which must be overcome to overshoot the boundary layer inversion. In the presence of moist convection this regulation mechanism will be fundamentally modified since the boundary layer will become an open thermodynamic system, with a valve, the cumulus mass flux, further regulating the moist static energy of the mixed layer (Gentine et al. 2013). 


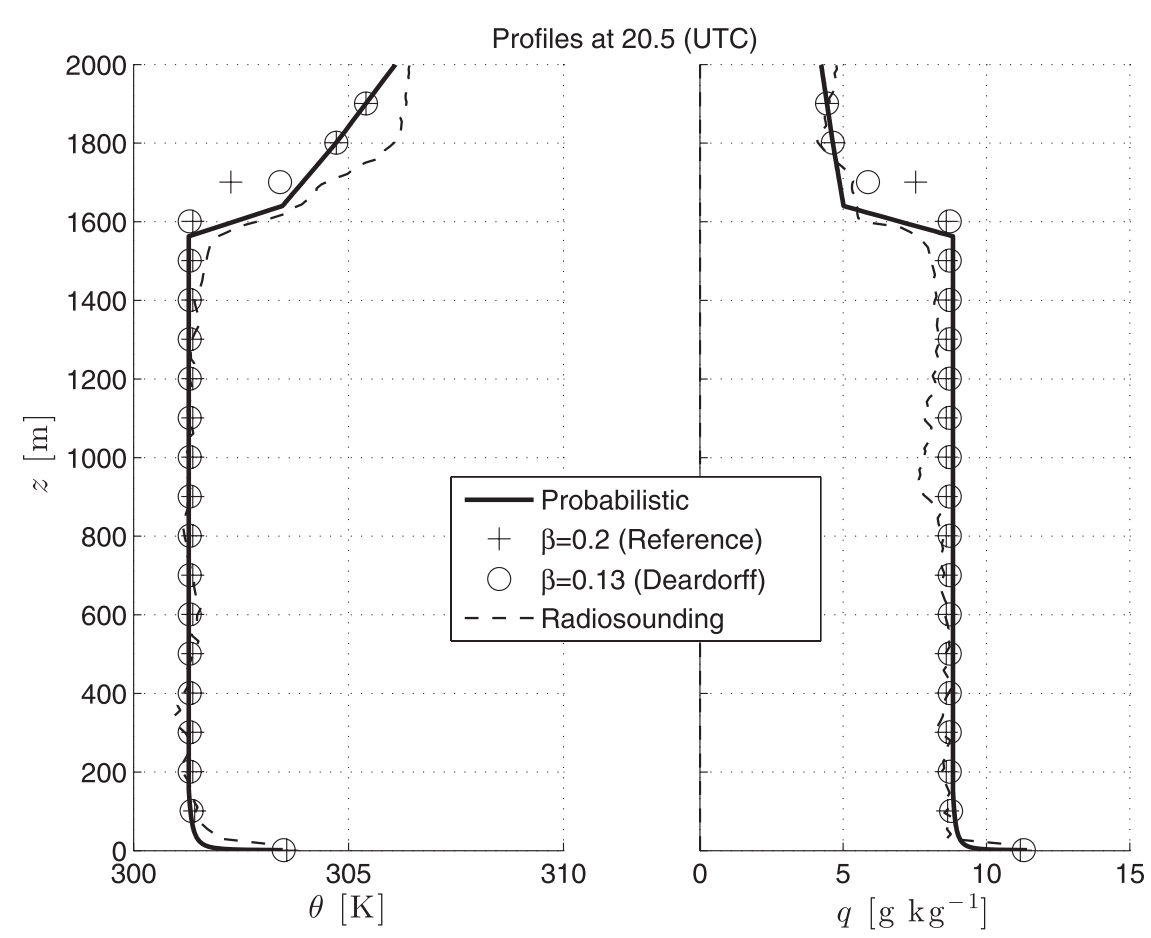

FIG. 11. Profiles of (left) potential temperature and (right) specific humidity at 2030 UTC 5 Jun 1997 for the ARM SGP site in Oklahoma.

\section{Discussion and conclusions}

A new formulation of the entrainment velocity of the dry mixed layer has been presented, which relates the entrainment velocity to the mass flux of the dry thermals overshooting the boundary layer inversion. The mass flux is itself related to the probability density function of vertical velocity $w$, potential temperature $\theta$, and specific humidity $q$ in the lower mixed layer.

An advantage of the probabilistic formulation is that it does not impose any constant relationship between the top-of-the-mixed-layer buoyancy flux and the surface value. Instead, the entrainment velocity can evolve as a function of time and in response to the environmental profile. Another advantage of the probabilistic formulation, which is discussed in a companion paper of this study (Gentine et al. 2013), is that the entrainment velocity and cloud-base mass flux can be described through a single, complementary formulation.

This new probabilistic framework compares well with large-eddy simulations in the cases of a convective boundary layer capped with a weak inversion and with a strong inversion. The model also compares well against observations from the Atmospheric Radiation Measurement Program (ARM). This new probabilistic formulation allows for a dynamical response of the boundary layer entrainment velocity coefficient (ratio of top to surface buoyancy flux), which depends on surface heating and on the environmental profile. The model, called the probabilistic bulk coupled model (PBCM), is relatively insensitive to the exact formulation of the joint surface probability density function. The dry inversion depth in fact adapts to changes in the surface variance parameterization and regulates the dry convective inhibition. The new dry boundary layer scheme is consequently robust. The model is mostly sensitive to the definition of the initial environmental profile and stability, as well as to the lateral plume entrainment. PBCM has analytical solutions and is therefore computationally very efficient. In addition, no discretization is needed, which allows for process-level studies and testing of various physical mechanisms and parameters.

The verification of the validity of the model in a dry case is a necessary step toward its development to unify

TABLE 2. Sensitivity of PBCM variables to the main model parameters at the end of the simulation.

\begin{tabular}{lcccc}
\hline \hline \multicolumn{1}{c}{ Variable } & $1.5 \operatorname{var}(w)$ & $1.5 \operatorname{var}(\theta)$ & $1.5 \operatorname{var}(q)$ & $1.5 \epsilon$ \\
\hline$\Delta \max \left(z_{m}\right)(\%)$ & 0 & 2 & 0.5 & -6 \\
$\Delta \max (\theta)(\mathrm{K})$ & -0.01 & 0.033 & -0.027 & -0.077 \\
$\Delta \max (q)(\%)$ & 0 & -1 & -0.2 & 2 \\
\hline
\end{tabular}



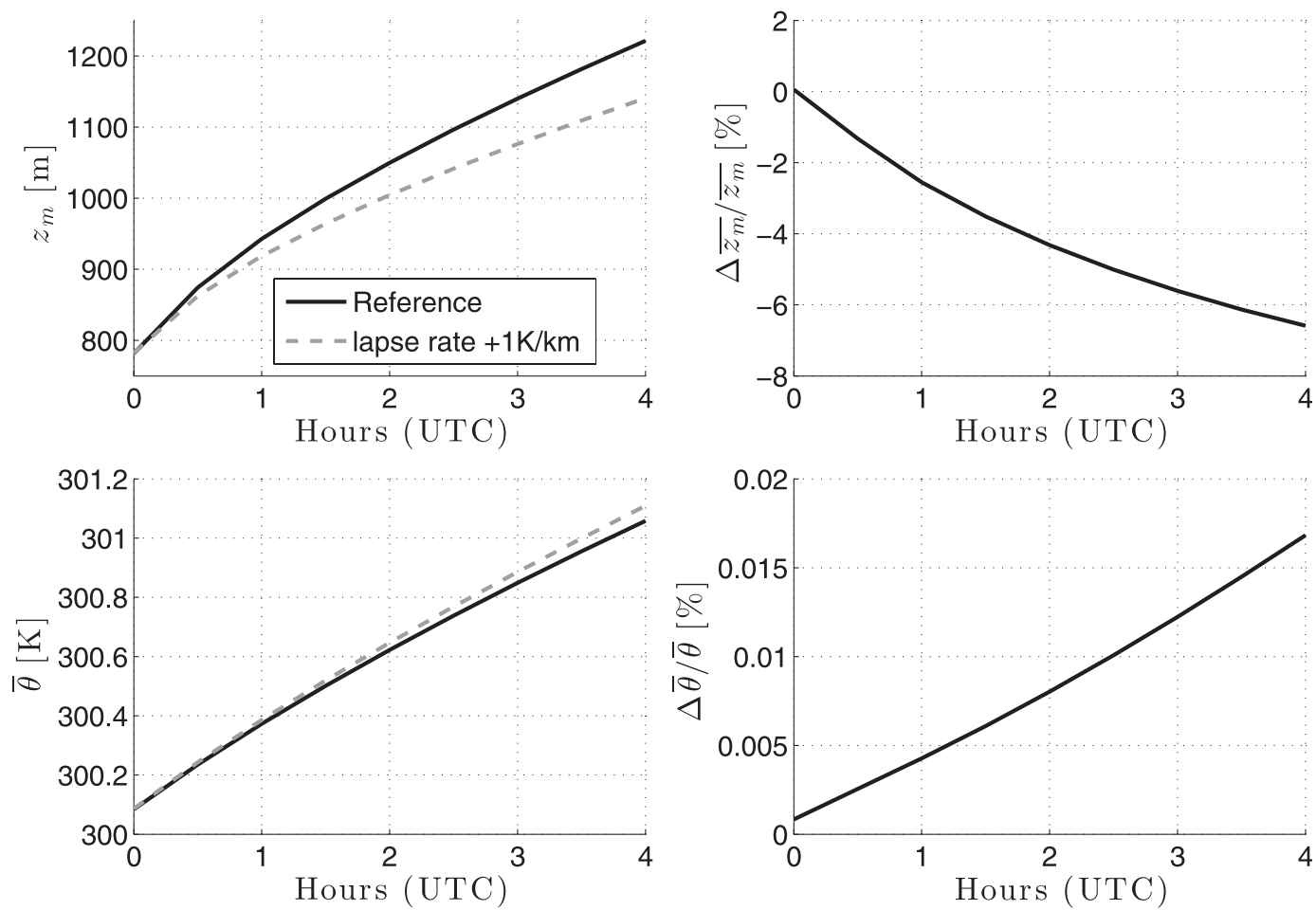

FIG. 12. Sensitivity of (top) mixed-layer growth and (bottom) mixed-layer potential temperature. The continuous line represents the reference run, and the dashed line represents the response of the model with a $1 \mathrm{~K} \mathrm{~km}^{-1}$ lapserate increase in potential temperature. (left) Absolute response and (right) percentage response.

dry and shallow-cumulus-topped boundary layers within a single framework. Indeed, the definition of the entrainment velocity as a mass flux permits a natural coupling between the mixed-layer entrainment velocity and the convective cloud mass flux, which is developed in a companion paper.

The code of the model as well as the test cases used in this publication can be downloaded on the first author's website at www.gentine.com or by sending an e-mail to the first author.

Acknowledgments. This work was carried out under Grant NSF-AGS 1035843: Collaborative Research: Quantifying the Impacts of Atmospheric and Land Surface Heterogeneity and Scale on Soil MoisturePrecipitation Feedbacks and NSF Grant AGS-0529797: Surface, Boundary Layer and Cloud Interactions of Energy, Water and Carbon Dioxide (CO2). The authors wish to thank Adam Sobel, Jean-Christophe Golaz, Andrew Majda, Catherine Rio, Nicolas Rochetin, Joseph Santanello, Zhiming Kuang, Daehyun Kim, Sylvain Cheinet, Elie Bou-Zeid, David Romps, and Larry Berg for their valuable comments and feedback on our work, as well as Pier Siebesma and Andy Brown for their help. We also would like to thank four anonymous reviewers for their valuable comments.

\section{APPENDIX}

\section{Analytical Derivations}

\section{a. Conserved variables}

Within the mixed layer the conserved variables can be written analytically by integrating Eq. (2):

$$
\phi_{u}^{\prime}(z)=\phi^{\prime}(0) \exp (-\epsilon z)
$$

The updraft velocity can be integrated as well and yields

$w_{u}^{2}(z)=\frac{\left[2 \exp (-\epsilon z)-2 \exp \left(-2 c_{2} \epsilon z\right)\right] \theta_{v}^{\prime}(0) g c_{1}}{\epsilon\left(2 c_{2}-1\right) \bar{\theta}_{v}}$

in which the second-order variations in virtual potential temperature have been neglected $\theta_{v}^{\prime}=\theta^{\prime}+\bar{\theta} \gamma q^{\prime}$ with $\gamma=0.622$.

In the inversion layer, the conserved variables are found by continuity on top of the mixed-layer $z_{m}$ :

$$
\begin{aligned}
\phi_{u}^{\prime}(z)= & \Gamma_{z_{m}}^{\phi}\left(z-z_{m}-\frac{1}{\epsilon}\right)+\frac{\exp \left[-\epsilon\left(z-z_{m}\right)\right]}{\epsilon} \\
& \times\left[\Gamma_{z_{m}}^{\phi}+\exp \left(-\epsilon z_{m}\right) \epsilon \phi_{u}^{\prime}(0)\right] .
\end{aligned}
$$

In the same way, the updraft vertical velocity is 


$$
w_{u}^{2}(z)=c_{1} g \frac{2 \Gamma_{z_{m}^{v}}^{\theta_{v}} e^{-\epsilon\left(z-z_{m}\right)} c_{2}-2 e^{-2 c_{2} \epsilon z} \theta_{v}^{\prime}(0) \epsilon c_{2}-2 c_{2} \Gamma_{z_{m}^{v}}^{\theta_{v}}+2 c_{2} e^{-\epsilon z} \theta_{v}^{\prime}(0) \epsilon-e^{-2 c_{2} \epsilon\left(z-z_{m}\right)} \Gamma_{z_{m}^{v}}^{\theta_{v}}+\Gamma_{z_{m}^{v}}^{\theta_{v}}}{c_{2} \epsilon^{2} \theta_{v}\left(2 c_{2}-1\right)}
$$

\section{b. Entrainment velocity at the boundary layer top}

The entrainment velocity is found analytically by computing the mean expected vertical velocity of the updrafts, according to their Gaussian pdf. The solution to the integral is

$$
\begin{aligned}
w_{e}= & \frac{1}{4} \exp \left(-\frac{1}{4} \frac{B^{2}}{A^{2} \sigma_{\theta_{v}}^{2}}\right) B^{2} \\
& \times \frac{\operatorname{BesselK}\left(\frac{3}{4}, \frac{1}{4} \frac{B^{2}}{A^{2} \sigma_{\theta_{v}}^{2}}\right)-\operatorname{BesselK}\left(\frac{1}{4}, \frac{1}{4} \frac{B^{2}}{A^{2} \sigma_{\theta_{v}}^{2}}\right)}{\sqrt{-B \pi} \sigma_{\theta_{v}}},
\end{aligned}
$$

with

$$
\begin{aligned}
A= & \frac{2 c_{1} g}{\overline{\theta_{v}}\left(2 c_{2}-1\right) \epsilon}\left(e^{-\epsilon h}-e^{-2 c_{2} \epsilon h}\right) \text { and } \\
B= & \frac{c_{1} g}{c_{2} \epsilon^{2} \overline{\theta_{v}}\left(2 c_{2}-1\right)} \\
& \times \Gamma_{z_{m}^{v}}^{\theta_{v}}\left\{2 c_{2}\left[e^{-\epsilon\left(h-z_{m}\right)}-1\right]-e^{-2 c_{2} \epsilon\left(h-z_{m}\right)}+1\right\} .
\end{aligned}
$$

\section{REFERENCES}

Albrecht, B., 1979: Model of the thermodynamic structure of the trade-wind boundary layer: Part II. Applications. J. Atmos. Sci., 36, 90-98.

— A. K. Betts, W. Schubert, and S. Cox, 1979: Model of the thermodynamic structure of the trade-wind boundary layer: Part I. Theoretical formulation and sensitivity tests. J. Atmos. Sci., 36, 73-89.

Ansmann, A., J. Fruntke, and R. Engelmann, 2010: Updraft and downdraft characterization with Doppler lidar: Cloud-free versus cumuli-topped mixed layer. Atmos. Chem. Phys., 10, $7845-7858$.

Batchvarova, E., and S.-E. Gryning, 1994: An applied model for the height of the daytime mixed layer and the entrainment zone. Bound.-Layer Meteor., 71, 311-323.

Beljaars, A. C. M., and A. A. M. Holtslag, 1991: Flux parameterization over land surfaces for atmospheric models. J. Appl. Meteor., 30, 327-341.

Bellon, G., and B. Stevens, 2005: On bulk models of shallow cumulus convection. J. Atmos. Sci., 62, 3286-3302.

Betts, A. K., 1973: Non-precipitating cumulus convection and its parameterization. Quart. J. Roy. Meteor. Soc., 99, 178-196.

_ 1974: Non-precipitating convection and its parameterizationReply. Quart. J. Roy. Meteor. Soc., 100, 469-471.

_ 1975: Parametric interpretation of trade-wind cumulus budget studies. J. Atmos. Sci., 32, 1934-1945.
Bony, S., B. Stevens, I. Held, J. Mitchell, and J. Dufresne, 2011: Carbon dioxide and climate: Perspectives on a scientific assessment. Preprints, WCRP Open Science Conf., Denver, CO, WCRP, 1-17. [Available online at http://www.wcrp-climate. org/conference2011/documents/LongTermClimateChange_ Bony.pdf.]

Bretherton, C. S., and S. Park, 2008: A new bulk shallow-cumulus model and implications for penetrative entrainment feedback on updraft buoyancy. J. Atmos. Sci., 65, 2174-2193.

Cheinet, S., 2003: A multiple mass-flux parameterization for the surface-generated convection. Part I: Dry plumes. J. Atmos. Sci., 60, 2313-2327.

_ 2004: A multiple mass-flux parameterization for the surfacegenerated convection. Part II: Cloudy cores. J. Atmos. Sci., 61, 1093-1113.

Clayson, C. A., and L. Kantha, 2008: On turbulence and mixing in the free atmosphere inferred from high-resolution soundings. J. Atmos. Oceanic Technol., 25, 833-852.

Conzemius, R., and E. Fedorovich, 2007: Bulk models of the sheared convective boundary layer: Evaluation through large eddy simulations. J. Atmos. Sci., 64, 786-807.

Couvreux, F., F. Hourdin, and C. Rio, 2010: Resolved versus parametrized boundary-layer plumes. Part I: A parametrizationoriented conditional sampling in large-eddy simulations. Bound.-Layer Meteor., 134, 441-458.

Deardorff, J. W., 1976: Entrainment rate of stratocumulus-topped mixed layer. Quart. J. Roy. Meteor. Soc., 102, 563-582.

_ 1979: Prediction of convective mixed-layer entrainment for realistic capping inversion structure. J. Atmos. Sci., 36, 424436.

—_, and G. Willis, 1980: Laboratory studies of the entrainment zone of a convectively mixed layer. J. Fluid Mech., 100, 4164.

De Bruin, H., B. van den Hurk, and L. Kroon, 1999: On the temperature-humidity correlation and similarity. Bound.Layer Meteor., 93, 453-468.

De Rooy, W. C., and P. Siebesma, 2008: A simple parameterization for detrainment in shallow cumulus. Mon. Wea. Rev., 136, 560-576.

Dillon, T. M., 1982: Vertical overturns: A comparison of Thorpe and Ozmidov length scales. J. Geophys. Res., 87 (C12), 96019613.

Fedorovich, E., R. Conzemius, and D. Mironov, 2004: Convective entrainment into a shear-free, linearly stratified atmosphere: Bulk models reevaluated through large eddy simulations. J. Atmos. Sci., 61, 281-295.

Garratt, J., 1994: The Atmospheric Boundary Layer. Cambridge University Press, $336 \mathrm{pp}$.

Gentine, P., A. K. Betts, B. R. Lintner, K. L. Findell, C. C. van Heerwaarden, and F. D'Andrea, 2013: A probabilistic bulk model of coupled mixed layer and convection. Part II: Shallow convection case. J. Atmos. Sci., 70, 1557-1576.

Golaz, J., V. Larson, and W. Cotton, 2002: A PDF-based model for boundary layer clouds. Part I: Method and model description. J. Atmos. Sci., 59, 3540-3551.

Heus, T., and Coauthors, 2010: Formulation of the Dutch Atmospheric Large-Eddy Simulation (DALES) and overview of its applications. Geosci. Model Dev., 3, 415-444. 
Hourdin, F., F. Couvreux, and L. Menut, 2002: Parameterization of the dry convective boundary layer based on a mass flux representation of thermals. J. Atmos. Sci., 59, 1105-1123.

Jakob, C., and A. Siebesma, 2003: A new subcloud model for massflux convection schemes: Influence on triggering, updraft properties, and model climate. Mon. Wea. Rev., 131, 2765-2778.

Kuang, Z., and C. S. Bretherton, 2006: A mass-flux scheme view of a high-resolution simulation of a transition from shallow to deep cumulus convection. J. Atmos. Sci., 63, 1895-1909.

Lappen, C., and D. A. Randall, 2001: Toward a unified parameterization of the boundary layer and moist convection. Part I: A new type of mass-flux model. J. Atmos. Sci., 58, 2021-2036.

Lenschow, D., 1973: Two examples of planetary boundary layer modification over the Great Lakes. J. Atmos. Sci., 30, 568-580.

Lilly, D. K., 1968: Models of cloud-topped mixed layers under a strong inversion. Quart. J. Roy. Meteor. Soc., 94, 292-309.

Lothon, M., F. Couvreux, S. Donier, and F. Guichard, 2007: Impact of coherent eddies on airborne measurements of vertical turbulent fluxes. Bound.-Layer Meteor., 124, 425-447.

Mellado, J. P., B. Stevens, H. Schmidt, and N. Peters, 2010: Probability density functions in the cloud-top mixing layer. New $J$. Phys., 12, 085010, doi:10.1088/1367-2630/12/8/085010.

Neggers, R. A. J., B. Stevens, and J. D. Neelin, 2007: Variance scaling in shallow-cumulus-topped mixed layers. Quart. J. Roy. Meteor. Soc., 133, 1629-1641.

—, M. Koehler, and A. C. M. Beljaars, 2009: A dual mass flux framework for boundary layer convection. Part I: Transport. J. Atmos. Sci., 66, 1465-1487.

Pino, D., J. Vila-Guerau de Arellano, and S.-W. Kim, 2006: Representing sheared convective boundary layer by zeroth- and first-order-jump mixed-layer models: Large-eddy simulation verification. J. Appl. Meteor. Climatol., 45, 1224-1243.

Rio, C., and F. Hourdin, 2008: A thermal plume model for the convective boundary layer: Representation of cumulus clouds. J. Atmos. Sci., 65, 407-425.
Santanello, J. A. J., M. Friedl, and W. Kustas, 2005: An empirical investigation of convective planetary boundary layer evolution and its relationship with the land surface. J. Appl. Meteor., 44, 917-932.

Siebesma, A., and Coauthors, 2003: A large eddy simulation intercomparison study of shallow cumulus convection. J. Atmos. Sci., 60, 1201-1219.

Simpson, J., and V. Wiggert, 1969: Models of precipitating cumulus towers. Mon. Wea. Rev., 97, 471-489.

— , R. H. Simpson, D. A. Andrews, and M. A. Eaton, 1965: Experimental cumulus dynamics. Rev. Geophys., 3, 387-431.

Soares, P., P. Miranda, A. Siebesma, and J. Teixeira, 2004: An eddy-diffusivity/mass-flux parametrization for dry and shallow cumulus convection. Quart. J. Roy. Meteor. Soc., 130, 33653383.

Stevens, B., 2002: Entrainment in stratocumulus-topped mixed layers. Quart. J. Roy. Meteor. Soc., 128, 2663-2690.

_ 2006: Bulk boundary-layer concepts for simplified models of tropical dynamics. Theor. Comput. Fluid Dyn., 20, 279-304.

Stull, R. B., 1973: Inversion rise model based on penetrative convection. J. Atmos. Sci., 30, 1092-1099.

_ 1976a: Energetics of entrainment across a density interface. J. Atmos. Sci., 33, 1260-1267.

_ 1976b: Internal gravity waves generated by penetrative convection. J. Atmos. Sci., 33, 1279-1286.

—, 1988: An Introduction to Boundary Layer Meteorology. Springer, $666 \mathrm{pp}$.

Sullivan, P., C. Moeng, B. Stevens, D. Lenschow, and S. Mayor, 1998: Structure of the entrainment zone capping the convective atmospheric boundary layer. J. Atmos. Sci., 55, 3042-3064.

Tennekes, H., 1973: A model for the dynamics of the inversion above a convective boundary layer. J. Atmos. Sci., 30, 558-567.

vanZanten, M. C., P. Duynkerke, and J. Cuijpers, 1999: Entrainment parameterization in convective boundary layers. J. Atmos. Sci., 56, 813-828. 